\title{
AC 2007-657: OBSERVATIONS FROM A PROJECT TO ENCOURAGE MULTIPLE-YEAR, INTERNATIONAL COLLABORATION ON RESEARCH FOR UNDERGRADUATES
}

\section{Stephen Silliman, University of Notre Dame}

Stephen E. Silliman is a Professor of Civil Engineering and Geological Sciences and the Associate Dean for Undergraduate Programs in the College of Engineering at the University of Notre Dame. His primary area of research is in groundwater hydraulics and chemical transport. He has pursued research and educational programs in both Haiti and Benin (West Africa) involving both undergraduate and graduate students. 


\title{
Observations from a Project to Encourage Multiple-Year, International Collaboration on Research for Undergraduates
}

\begin{abstract}
Over the past 10 years, the author has experimented with a number of program formats designed to inform engineering undergraduates of the requirements of pursuing engineering projects in developing countries. These have included: (i) an elective course on water supply in developing countries, (ii) a service program in Haiti involving a combination of U.S. engineering and nonengineering undergraduates, (iii) an international REU program involving collaborative research in Benin (West Africa) among students from multiple universities in the U.S., and (iv) a recent experiment in multi-year research involving collaborations among U.S. undergraduates working with graduate students in Benin. A previous ASEE paper compared preliminary assessment of the first three types of programs (course, service, and REU). Results from this earlier assessment indicated that the multi-year program should represent a popular offering for U.S. undergraduates. Although the assessment of the first experience with the multi-year offering is limited by the number of student participants (4) such that the results must be interpreted with caution, the assessment leads to insight into the motivation, objectives, and constraints on an international, multi-year program. Among the positive outcomes are enhanced student appreciation (in both the US and Benin) of the potential benefit of international collaboration, recognition of common objectives (both educational and professional) among students from different cultures, and significant research results. Among the constraints not realized prior to this experience are the role that original student motivation has on long-term dedication to the project, the continuing language barriers that exist even after an 8-week common experience among the students, the challenge associated with disparate periods (in the two countries) during which the students have relatively free time to commit to the research effort, and the different educational philosophies of the two programs (U.S. and Benin).
\end{abstract}

\section{Introduction}

Over the past decades, a number of initiatives in engineering education that involve efforts beyond the classroom have been presented in the literature. In many cases, strong arguments can be made that such experiences have a positive impact on the undergraduate engineering experience. For example, significant experiments in service learning have demonstrated substantial impact on the educational experience of the undergraduate. These have included, for example, the substantial efforts in EPICS programs ${ }^{1}$, integration of service-learning into the engineering curriculum ${ }^{2}$, and use of service-learning as a means of addressing engineering ethics through application ${ }^{3}$. Similarly, research experiences for undergraduates have been shown to have substantial impact on the student experience ${ }^{4}$. Such research experiences are now considered fundamental to engineering education and are supported, for example, by the U.S. National Science Foundation through the Research Experience for Undergraduates program. Finally, there is increasing awareness of the need to consider the unique engineering requirements involved in working in developing countries, as demonstrated through U.S. organizations focused on developing countries (e.g., Engineering World Health, Engineers 
Without Borders, Engineers for a Sustainable World) and manuscripts describing the unique needs of engineering curricula taught in developing countries ${ }^{5,6}$.

Within this context of educational experiences beyond the classroom, the Department of Civil Engineering and Geological Sciences at the University of Notre Dame has experimented over the past decade with a number of different formats for providing undergraduate engineers in the United States with an introduction to engineering in developing countries. The formats have ranged from classroom and design projects at Notre Dame, in-country service projects (www.nd.edu/ silliman/Development/haiti), service-learning projects performed at Notre Dame in collaboration with in-country partners, in-country / short-term research with or without interaction with peers from the partner country ${ }^{7}$, and long-term research involving close collaboration with colleagues and peers in-country ${ }^{8}$.

In two previous papers ${ }^{7.9}$, we compared the classroom, interdisciplinary service, and short-term research models. Questions addressed in the earlier papers involved whether these offerings were effective in achieving overall learning objectives (outlined below) and whether the increased faculty time, financial burden and risk associated with international travel was warranted based on the experience obtained by the student. Results presented demonstrated that there was quantifiable additional benefit to pursuing an in-country field component as compared to limiting the experience to a classroom discussion (in terms of student recognition of the technical and social constraints present in a developing country and the opportunity to interact directly with the population in the developing country). The results from these earlier studies led to the design of a new model for international research that involves substantial interaction with peers and colleagues in-country and longer-term commitment of the U.S. students to the research program $^{8}$. The assessment of the first offering of this long-term research program is the focus of the present paper.

\section{The Long-Term Research Model (LTR)}

The long-term research model (LTR) was applied to a collaboration between the University of Notre Dame (UND) and the Universite d'Abomey-Calavi (UAC - the national university in Benin, West Africa). The LTR involves commitment by the UND students over two academic years. During the fall semester of the first year, the students apply, are accepted, and review the scope of their project. During the spring semester, the students complete (under the direction of a UND faculty member and for academic credit) background reading and initial studies of the techniques to be used in Benin. To the degree possible, initial communications are established with the research team in Benin (which is following a similar schedule, but with their "matrice", or masters, level students).

The UND students then travel to Benin for eight weeks during the summer between the first and second academic years (they are supported at a rate similar to the rate paid for typical REU sites - in addition, all travel expenses are paid). The initial two weeks involve completing a research course (taught jointly by faculty from UND and UAC) in collaboration with the Benin students. This provides an initial opportunity for bonding among the students (the course involves projects with teams comprised of students from both schools), initial efforts at increasing language skills, and initial recognition of similarities and differences among the academic backgrounds and strengths of the various students involved. The remaining 6 week period involves pursuit of 
research projects involving teams of UND students working with their Benin counterparts and, as appropriate, government organizations and the local population of Benin.

During the following fall and spring semesters, the research teams continue to pursue joint research, using the internet for all communication. The expectation is that each team will produce publishable results by the end of the spring semester of the second academic year.

In applying the LTR to the collaborative study being conducted by UND and UAC, the UND students included three engineering students (two sophomores and one junior), as well as one sophomore anthropologist. Approximately 10 Benin students where involved in the course, with three students contributing to the research projects. In addition, one UND faculty member, two UAC faculty members, one UND graduate student, and a UND anthropologist were involved in the course and/or research components of this experience. The course taught in Benin involved modeling of groundwater flow and transport using a commercial modeling software package with licenses purchased for both UND and UAC.

Three project teams were established after completion of the course. These involved the anthropology student working on an education project in a local community without substantial interaction with Benin students, one engineering student working on characterization of uranium contamination in a local community in collaboration with a UND graduate student and one student from Benin, and the other two engineering students working with two students from Benin on an effort to model salt-water intrusion in coastal Benin.

\section{Learning Objectives}

The LTR shares two primary learning objectives with each of the other models previously investigated ${ }^{9}$ :

- Students will understand the challenges involved in pursuing engineering projects in developing countries (including technical, social, economic and political considerations).

- Students must work in a multidisciplinary team to identify solutions to one or more complex problems involving water resources in a developing country.

In addition, the LTR includes learning objectives that were common to at least one, but not all, of the previous models:

- Students must comprehend and incorporate non-technical considerations in their development of a project plan for a water resource project in a developing country.

- Students must gain significant appreciation for graduate-level research.

- Students must work with students / faculty from developing country partner institutions.

Finally, the LTR introduced the following additional learning objectives: 
- Students must develop research hypotheses, design a research plan, and complete the research program all in collaboration with their in-country peers.

- The students must pursue this research program with the intent of producing a publishable product by the end of the second academic year.

\section{Assessment Tools}

We have applied a number of assessment tools to the comparison of these various models (analysis of results for the earlier models are presented elsewhere ${ }^{9}$ ). These tools include:

- A common survey administered to student participants and a control group on expectations of an undergraduate curriculum in engineering.

- Surveys administered to student participants and a control group comparing expectation versus experience in their undergraduate curriculum.

- Student evaluations of their experience.

- Statistics on the gender mix of applicants and participants in each model.

- Post-graduation activities (or planned post-graduation activities).

The use of surveys follows on the common practice of the use of surveys as assessment instruments ${ }^{4,10,11}$.

For the LTR, we added a number of model-specific questions to the student evaluation. Further, we evaluated ongoing student interest in the research projects. As our sample size based on our first experience with the LTR is extremely small (3 total engineers and 4 total students), the analysis below focuses primarily on the ongoing student interest in the LTR and the questions listed in Table 1 which were added to the survey (the survey was administered at the beginning of the spring semester in the second academic year). It is recognized that any conclusions from these limited results must be considered preliminary and should be supplemented by assessment of the experiences of future student participants.

\section{Size and Gender Mix of Applicant Pool}

In terms of numbers of applicants, both the service-learning and short-term research programs attracted considerable interest. In any particular offering, the service-learning opportunity attracted between 30 and 70 applications (all from UND) to fill approximately 8 positions. Similarly, the short-term research program attracted between 50 and 80 applications (from throughout the United States) for each of the three summers that this program was active. 
Table 1: Questions unique to the survey tool used with the LTR.

\begin{tabular}{|c|c|}
\hline \multicolumn{2}{|r|}{$\begin{array}{c}\text { The students were asked to respond to the following on a scale of 1-5 }(1=\text { strongly } \\
\text { disagree, } 5=\text { strongly agree })\end{array}$} \\
\hline 1 & $\begin{array}{l}\text { This experience contributed in a positive way to my view of the interplay between my } \\
\text { educational major (e.g., engineering, anthropology, etc) and society. }\end{array}$ \\
\hline 2 & $\begin{array}{l}\text { Based on this experience, I have a greater appreciation for the challenges and potential } \\
\text { benefits of interacting with colleagues and/or friends in a developing country. }\end{array}$ \\
\hline 3 & $\begin{array}{l}\text { This experience led me to believe that the students whom I met in Benin have essentially } \\
\text { the same professional and life goals as I do (although differences in education may } \\
\text { impact the degree to which each of us can attain those goals). }\end{array}$ \\
\hline 4 & $\begin{array}{l}\text { My particular project provided a positive experience in terms of the interactions with the } \\
\text { people of Benin. }\end{array}$ \\
\hline 5 & $\begin{array}{l}\text { My particular project provided a positive experience in terms of the interactions with my } \\
\text { Beninoise colleagues. }\end{array}$ \\
\hline 6 & $\begin{array}{l}\text { My particular project provided a positive experience in terms of the research that was } \\
\text { performed and/or exposure to the process of performing research in a graduate program. }\end{array}$ \\
\hline 7 & $\begin{array}{l}\text { The language barrier was not a significant issue by the end of the project period (project } \\
\text { period defined as the end of the time in Benin for the ladies in Adourekoman and as the } \\
\text { end of the fall semester for the modeling group). }\end{array}$ \\
\hline \multicolumn{2}{|r|}{ The students were asked to provide short answers to the following questions } \\
\hline 8 & $\begin{array}{l}\text { Thinking back on when you applied for this program, how would you characterize your } \\
\text { motivation for becoming involved? In particular, do you believe that you were more } \\
\text { motivated by the opportunity to pursue research, the opportunity to work in Benin, } \\
\text { religious/spiritual motivations, or other motivations? }\end{array}$ \\
\hline 9 & $\begin{array}{l}\text { Thinking back on when you applied for this program, how would you characterize your } \\
\text { primary objective(s) for becoming involved? (e.g., you wanted to determine your own } \\
\text { interest in pursuing a research career, you wanted to determine your own interest in a } \\
\text { future career in development, you wanted to expand your life experience to include } \\
\text { living in a developing country, or other objectives ...). }\end{array}$ \\
\hline 10 & $\begin{array}{l}\text { Do you believe that your objective(s) was(were) met? (Mote that this does NOT } \\
\text { necessarily mean that you obtained the experience you anticipated. For example, if your } \\
\text { objective was to determine your own interest in pursuing a research career, a decision } \\
\text { that research is no longer of interest to you would be a successful completion of your } \\
\text { objective, even if you were hoping that you would fall in love with research.) }\end{array}$ \\
\hline 11 & $\begin{array}{l}\text { If you have decided not to continue with this program (either in the spring semester or } \\
\text { decided not to apply again for the summer of 2007), what is(are) the major constraint(s) } \\
\text { that led to your decision not to continue? }\end{array}$ \\
\hline
\end{tabular}


In comparison to these substantial responses to the previous models, interest expressed in the LTR model has been quite limited. Over the first two years, we have received a total of approximately 20 applications (i.e., an average of approximately 10 per year). Further, a significant number of these applications are from students with academic records that would not immediately be recognized as the top candidates for conducting independent research in the focus area of the work in Benin (water quality and numerical modeling). Incompatibilities in the student records were related to GPA, major, class year, and distribution of their course work. It is suggested that the low turn-out for applications may be related to at least four factors. First, the skill sets required for the LTR (including at least a minimal level of language skills and interest in an extended research experience) likely reduced the population of students who would consider themselves eligible for the program. Second, one group of students who had initially indicated interest in applying for this program, but eventually did not apply, indicated that the time commitment of the program was intimidating within the context of their undergraduate engineering curriculum. Specifically, several of the curricula in the College of Engineering at UND contain only 2 discipline-specific electives and one general technical elective.

Participation in the LTR would effectively use all of these electives, thus reducing opportunities for the students to pursue other interests within engineering. Third, another group of students who had indicated interest in the program, but did not apply, indicated that they were pursuing other opportunities which UND offers to engineering intents during the summer period. Finally, in advertising the application for the LTR, we used only the project web site and a bulk email to announce the availability of the application and the application due date. At least one student reported that the bulk email, despite coming from the office of the Dean of Engineering, was inadequate to gain the attention of the student body, particularly given that the email appeared in the latter half of the semester.

As a result of the substantial interest in gender issues within engineering ${ }^{12,13,14}$, gender distribution of applications to the service-learning, short-term research, and LTR programs have been recorded and assessed. In this regard, the results for the LTR are consistent with, or possibly indicate an even larger bias towards women than, the results obtained in the previous models. As noted in a prior paper ${ }^{9}$, the application pool for the service-learning and short-term research programs consisted of between 50 and 56 percent women. It was argued that the significant over-representation of women in the application pools (as compared to the overall population of undergraduate engineers) was likely related to the societal context of those service and research opportunities. For the LTR, the gender distribution in the application pool was approximately $70 \%$ women. We are cautious, due to the low numbers of total applicants, to state that this result provides strong evidence that the LTR further increases bias towards women: however, it is clear that, as with the previous programs, woman are applying to this program in percentages that are well above the overall percentage of women in our undergraduate engineering curricula.

\section{Interview and Survey Results}

Each of the students involved in the first year of the LTR was interviewed multiple times throughout the LTR program to determine enthusiasm for the ongoing efforts. Based on these interviews, the students involved were broadly grouped into one of three categories based on the history of their responses to these interviews (this grouping was identified from all interviews performed and only at the end of the project). 
- Category 1 (C1): Prior to traveling to Benin, the two students in this category (one engineer and the anthropology student) took the research programs extremely seriously and regularly challenged prior research efforts related to the Benin project (in both the engineering and anthropological aspects). Once in Benin, they took active roles in leading their team research efforts. These students were natural leaders and clearly felt comfortable taking control of their projects in Benin. In one case, one of these students was somewhat overconfident and intervention was required to reduce this student's level of aggressiveness so as to encourage more collaborative decision making with the research team. Following the return to UND, these two students continued to actively pursue their projects. Except for a health concern in one of these students, both students were willing to return to Benin during the second summer (one will actually return).

- Category 2 (C2): Prior to traveling to Benin, the student in this category actively contributed to the research program, including challenging prior research results. Once in Benin, this student took a leadership role both within the project teams active during the course period and during the research period. Enthusiasm for the project dropped during the fall semester as the student developed interests in other topics in engineering. This student opted to withdraw from the LTR prior to the start of the spring semester of the second academic year. Reasons for this withdrawal included increasing interest in another area of engineering and a loss of interest in numerical modeling.

- Category (C3): Prior to traveling to Benin, the student in this category worked very hard under the direction of the UND graduate student to understand the equipment and sampling techniques. Once in Benin, this student was somewhat reluctant to command a leadership role in the research program, but was very efficient in pursuing the research and developing / maintaining new sampling protocols. Upon return to UND, this student worked under the direction of the UND graduate student to refine the analytical techniques necessary for sample analysis and analyzed a series of colloid samples collected in Benin. Given the opportunity to join the team for a second summer in Benin, this student initially opted out, citing a need to pursue summer internship opportunities so as to better pursue a job in industry following graduation. This student latter changed this decision and will continue with the project through the coming summer.

Based on the interviews, several observations were made regarding the LTR model and the student appreciation of this model. First, each of the students (including the C2 student who left the project early) evolved during the past year to have a significantly greater appreciation of the meaning of technical research, the challenges involved in technical research, the additional challenges introduced by working in a developing country and in a second language, and the challenge involved in using technical research to address specific, societal environmental and/or educational issues in a developing country.

Second, the students were relatively consistent in identifying the more difficult challenges which developed during the first year of the LTR. These included health concerns, differences in culture (in particular, challenges involving gender roles and the strict hierarchical governing structure in rural Benin), and barriers related to language (including both inability to speak the local language in the rural village and misunderstandings related to limited knowledge of the nuances of the language of partner students). Significantly, language barriers made internet 
communication related to continuing the project into the fall semester of the second academic year challenging for the students involved.

Third, students from both universities came to appreciate their similarities, but also the differences, in their educational backgrounds. In particular, the UAC students with whom we collaborated were very intelligent, were extremely hard workers and would fulfill all tasks requested of them. In general, however, their background gave them fewer tools with which to react to new or unforeseen changes in the research plan than were available to the UND students. The UAC students also have far fewer opportunities to work with computers, computer models, or mathematical models. In contrast, the UND students were quite good at the computing and math requirements of the project and had the tools required to adapt to changing project constraints. They were far less familiar than their UAC peers, however, with the field aspects of their effort. Further, they were less prepared to deal with the realities of working with the local population. As such, as the language barriers became less significant, the teams consisting of UAC and UND students became increasingly effective based on their diverse and complementary talents.

Fourth, in addition to the language barriers, differences in school schedules and technology led to a number of challenges during the fall semester following the summer period. Specifically, examination periods at UAC coincided with the initial portion of the fall academic calendar at UND, thus making initial efforts at establishing continuing research via the internet more difficult (the UAC students work full time on exams during this period). Further, vacation periods at UND led to periods in which communication with students at UAC was difficult or absent. Finally, time difference (UAC is six hours later than UND) combined with irregular availability of the internet in Benin led to unreliable communications during select periods of the fall semester.

Beyond the interviews, the surveys, completed and assessed following the fall semester (second academic year), provided corroboration of the interview results, as well as additional insight into student opinion. Although the number of survey responses from which to make conclusions is very limited (4), the results are generally consistent with the results obtained from the interviews. Due to the small sample size, the results are presented with caution with respect to over interpreting these results.

In terms of the survey responses, the most significant difference among the three student categories was the response of the students regarding their original motivation and objectives for applying to the program (Table 1, questions 8 and 9). The two $\mathrm{C} 1$ students clearly articulated a desire for an experience which combined a research experience with an opportunity to complete that research in a service-oriented environment. Both expressed that the combination of research and service, rather than either of these in isolation, was the motivation for applying for the program and formed the foundation of the objectives they had for the experience. The $\mathrm{C} 2$ student expressed more ambiguous motivations and objectives. In terms of motivation, the student listed spiritual / religious reasons as well as opportunities for academic research, but did not specifically outline a desire to pursue service. In terms of objectives, the student listed both a desire to determine if grad school was desirable and a desire to work on a project that was critical to a local population in a developing country. This student indicated that a primary objective was not met because the project to which this student contributed was not complete at the end of 
the program period (question 10, Table 1). Finally, the $\mathrm{C} 3$ student expressed that the primary motivation was a service experience in a developing country. Significantly, the only place within the essay responses where this student mentioned the term "research" was in explaining why the student was (initially) not returning to Benin: the student indicated that, given the research experience obtained in the program, an internship experience was a higher priority for the coming summer.

In addition to these differences in response to questions 8 and 9 (Table 1), a number of observations were suggested by the survey responses:

1. All responses were very positive (4's and 5's) with respect to questions 1-5. These positive responses are significant as a primary limitation of the previous models (the servicelearning and short-term research) was that the students had only limited opportunity to interact with either the local population or their colleagues in the project country. Although not surprising given the extended period of time in Benin, the response form the LTR students shows that providing a structure whereby students are working in teams directly with their colleagues has a significant, positive net impact on the overall international experience. This is consistent with other models for international collaboration which have been published in the literature ${ }^{15,16}$.

2. There was a significant difference among the student categories with respect to question 7. Specifically, the $\mathrm{C} 1$ and $\mathrm{C} 2$ students indicated that language was either no longer a barrier or only a slight barrier at the end of the summer period (as indicated by scores of 4 and 5 to this question). It is significant to note that two of these students knew essentially no French when the project started. In contrast, the $\mathrm{C} 3$ student scored this question as a 2: language was still viewed as a barrier. Although there were several factors that contributed to this difference (including training in French prior to travel, degree of independence in Benin, the language spoken in the local village where the $\mathrm{C} 3$ student was working, and living arrangements), this difference in response is considered, at least in part, an indicator of the difference in the perceived importance of taking a leadership role, and seeking collaboration with the local population, in the research portion of the in-country efforts.

3. There was a small difference in response to the quality of the research experience. Again, caution is urged on this comment given that assessment is based on only 4 responses. However, it is noted that the $\mathrm{C} 3$ student ranked the research experience as a 5, slightly higher than the 4's provided by the other students. One interpretation of this result which begs additional study is that the three students who were looking for a research experience were slightly more critical of that experience than was the student whose primary motivation was a service experience.

Finally, all students indicated a very positive experience, particularly in terms of teaming and exposure to other cultures. One of the students stated this best in the following comment provided near the end of the period in Benin:

I think all of us here have risen to meet them (the challenges of working in Benin) as individuals with ever growing leadership and at the same time, one of the greatest foundations of teamwork I have ever experienced... The idea of a socially conscious leader has changed for me ... 


\section{Discussion}

The Long-Term Research (LTR) Model has been assessed near the end of its initial cycle. Although the sample size is small (4 total students, 3 of which were engineering undergraduates), a number of observations are suggested by student interviews and the closing survey:

1. The student interviews, student surveys, and research results indicate that each of the learning objectives was met (with the exception of the final objective, production of publication-quality research, which remains on track for fulfillment prior to the end of the current academic year).

2. With respect to comparison of the LTR with the service-learning and short-term research experiences, there were several commonalities as well as significant differences:

- In common with the other models, the overall student response to the experience was very positive.

- In common with the other models, the experience provided the students with greater appreciation of the promise and constraints of working in developing countries.

- In contrast to the other models, the experience provided substantial opportunity for teaming and collaboration with peers and colleagues in Benin. As such this model joins other efforts ${ }^{15,16}$ in providing international research and educational experiences for engineering undergraduates that involve collaboration with peers from the partner country.

- In contrast to the other models, the experience provided the students an opportunity to understand the educational background and motivation of the students from Benin.

3. Despite all students being fully informed of the importance of the combination of the research and service components of this model at the beginning of the experience, it became apparent that the actual motivation for student involvement varied. Specifically, one student was motivated primarily by a desire for a service experience and another student was motivated primarily by a desire for spiritual and research experiences. The initial motivation appeared to have impact on the overall student experience, with student motivation to remain active in the project (and potentially contributing to an additional summer in Benin) tied to the desire to seek a service experience (either with or without the research experience).

\section{Acknowledgements}

This work is supported by the National Science Foundation (NSF 0138238). Support for this work from Dr. Moussa Boukari, Department des Sciences de la Terre, Universite d'AbomeyCalavi, Benin, was instrumental in providing team collaboration in Benin. 


\section{Bibliography}

1 - Coyle, E.J., L.H. Jamieson, and W. C. Oakes, 2005, "EPICS: Engineering Projects in Community Service”, Int. J. Engng Ed., 21(1), 139-150.

2 - Tsang, E., J. van Haneghan, B. Johnson, E.J. Newman, and S. van Eck, 2001, “A report on service-learning and engineering design: Service-learning's effect on students learning engineering design in 'Introduction to Mechanical Engineering"”, Int. J. Engng. Ed., 17(1), 30-39.

3 - Pritchard, M.S., 2000, "Service-learning and engineering ethics", Science and Engineering Ethics, 6(3), 413-422

4 - Zydney, AL, JS Bennett, A Shahid, and KW Bauer, 2002, "Impact of undergraduate research experience in engineering”, Jour of Engineering Education, 91(2), 151-157.

5 - Lewis, C., S. Magleby, and R. Todd, 2006, "Learning to design products in environments with limited design traditions", Int. J. Engng Ed, 22(3), 591-597.

6 - Fernando, S., N. Murali, and S. Bhushan, 2006, "The need to reform agricultural engineering curricula in developing countries”, Int. J. Engng. Ed., 22(1), 71-78.

7 - Silliman, S.E., M. Boukari, and P Crane, 2005, “A collaborative project in West Africa: Student research experience in development", Proceedings, FIE, fie.engrng.pitt.edu/fie2005/papers/1627.pdf

8 - Silliman, S.E., M. Boukari, and P. Crane, 2006, "International student collaboration through projects using common software and field experiences: Foundation to program development", Proceedings, Frontiers in Education, fie.engrng.pitt.edu/fie2006/papers/1524.pdf

9 - Silliman, S.E., 2003, "Comparison of education models for increasing student exposure to engineering in developing countries", Proceedings, ASEE, www.asee.org/acPapers/ 2003-2169_Final.pdf

10 - Downing, CG, 2001, "Essential non-technical skills for teaming”, Jour of Engineering Education, 90(1), 113117.

11 - Goodman Research Group, Inc., 2002, “Final report of the Women's Experiences in College Engineering (WECE) Project", Downloaded from www.grginc.com/WECE_FINAL_REPORT.pdf.

12 - Moskal, BM, 2000, "Looking to the future: Women in science and engineering", Conference Proceedings, $30^{\text {th }}$ annual Frontiers in Education Conference, Kansas City, Missouri, Vol. 1, F1B-19 - F1B-24A.Z.

13 - McLoughlin, LA, 2005, "Spotlighting: Energent gender bias in undergraduate engineering education”, J. Engng Ed., 94(4), 373-381.

14 - Ellis, GW, AN Rudnitsky, and GE Scordilis, 2005, "Finding meaning in the classroom: Learner-centered approaches that engage students in engineering", Int J Engng Ed., 21(6), 1148-1158.

15 - Qamhiyah, 2005,'Internationalization of the Undergraduate Engineering Program, Part 1: The Need", Int. J. Engng Ed., 21(1), 158-165.

16 - M. Barut, M.B. Yildirim, and K. Kilic, 2006, "Designing a Global Multi-Disciplinary Classroom: A Learning Experience in Supply Chain Logistics Management”, Int. J. Engng Ed., 22(5), 1105-1114. 